\title{
Performance Research of China's New Third Board Listed Companies-Based on the Semiconductor Industry
}

\author{
Chuman Yang \\ Department of Statistics, College of Economics, Jinan University, Guangzhou, China \\ Email: chumanyang@foxmail.com
}

How to cite this paper: Yang, C.M. (2019) Performance Research of China's New Third Board Listed Companies-Based on the Semiconductor Industry. Modern Economy, 10, 828-843.

https://doi.org/10.4236/me.2019.103055

Received: February 27, 2019

Accepted: March 19, 2019

Published: March 22, 2019

Copyright $\odot 2019$ by author(s) and Scientific Research Publishing Inc. This work is licensed under the Creative Commons Attribution International License (CC BY 4.0).

http://creativecommons.org/licenses/by/4.0/

\section{(c) (i) Open Access}

\begin{abstract}
This paper uses factor analysis, cluster analysis, discriminant analysis and other methods to conduct multivariate statistical analysis of the semiconductor industry, and evaluates the performance of the enterprise from the financial indicators of the enterprise. KMO test and Bartlett test show that the financial data of the semiconductor industry is very suitable for factor analysis. Through factor analysis and cluster analysis, this paper finally divides 71 semiconductor companies into four categories according to solvency, profitability, operational ability and growth ability, to provide a reference for investors.
\end{abstract}

\section{Keywords}

Semiconductor and Semiconductor Production Equipment Companies, Performance Evaluation, Factor Analysis, Cluster Analysis

\section{Introduction}

The full name of the New Third Board market is "National Small and Medium Enterprise Share Transfer System", which is the trading place for unlisted SMEs' share transfer services. The original purpose is to solve the NET system and the original tradable securities trading automatic quotation system and delisting from listed company. In 2013, the CSRC launched the second batch of expansion of the new three-board market area, including the national high-tech parks in Guangzhou High-tech Zone, Shenzhen High-tech Zone, and Chengdu High-tech Zone. As of December 2016, more than 1000 SMEs in China have already landed in the New Third Board market. With the gradual improvement of the "New Third Board" market system, its financing function has become increasingly ap- 
parent, and transactions will become increasingly active as the new three board market becomes active.

Although the semiconductor industry is a sunset industry in the semiconductor manufacturing industry in developed countries such as Western Europe. However, at the domestic macro level, this industry has very large commercial potential in China because it is an industry that the country urgently needs to develop and strongly support. Second, China has a semiconductor talent market that may not be the top but most abundant in the world. China has a huge labor cost advantage here, and Europe, the United States and Japan have also set up factories in the interior. The last market factor, as we all know, most of the world's electronic products are made in China, then the demand for semiconductor storage is also the largest, plus the industrial chain acquired by Ziguang, including Spreadtrum, Huasan, the western data of the shares, Sandisk, there are huge semiconductors storage needs. Therefore, it can be seen that due to the continuous development of the semiconductor industry, there will be more companies of this type entering the new three-board market, so it is necessary to study the business performance of such enterprises.

Many scholars have studied this. In the research of the New Third Board market, Zhou Maoqing and Yin Zhongli (2011) reviewed the development history of the New Third Board and analyzed its function and development trend [1]. Pan Yujun (2011) studied the transfer mechanism of the Chinese New Third Board [2]; Wei Shijie (2013) analyzed on the narrowly defined area of listed companies, the inability of ordinary natural persons to invest, and the backwardness of the trading system, proposed to promote the construction and system improvement of the New Third Board to improve the efficiency of corporate financing and venture capital withdrawal. In the aspect of financial crisis early warning research [3], Wu Xingze (2011) analyzed the main problems in the existing early warning research and proposed a new financial crisis early warning framework and analysis method [4]. Ye Huanzhen, Yang Qing and Wang Yonghua (2013) proposed a financial early warning and diagnosis model based on SABNM. Using genetic algorithm to search for optimal Bayesian network, using its forward reasoning for financial crisis early warning, using reverse reasoning to diagnose financial crisis causes, to avoid Limitations of statistical methods and deficiencies in artificial neural networks [5].

Based on the current economic background, the needs of investors in the New Third Board market and these studies, this paper summarizes the specific proportions of the more than 10,000 listed companies in the New Third Board, and uses the factor analysis method for the semiconductor and semiconductor manufacturing equipment industry and the energy industry. Statistical analysis is carried out by cluster analysis method, discriminant analysis method and face map analysis method. It is hoped that the analysis ideas and statistical models can be established from the perspective of stock market investors in the new three board market and provide investors with possible decision-making reference. 


\section{Overview of Enterprise Performance Evaluation}

Enterprise performance evaluation refers to quantitative and qualitative comparative analysis according to the specific index system and unified standards according to the specific index system and unified standards, and objectively analyzes the operating efficiency and the operator's performance during a certain period of operation. A fair and comprehensive evaluation.

The enterprise operating efficiency refers to the benefits that the enterprise obtains in the production and operation process, which can be understood as the profitability of the enterprise, the level of capital liquidity, the ratio of input and output, the capacity of debt repayment and the level of capital utilization.

According to the concept of enterprise performance evaluation, the performance of an enterprise is reflected by evaluating the operating efficiency of an enterprise and the performance of the operator.

\subsection{Solvency Indicator}

\section{1) Current ratio}

The current ratio is the ratio of current assets to current liabilities. It is used to measure the ability of a company's current assets to become cash for repayment of liabilities before the short-term debt expires. Current assets refer to assets that can be realized or used in an operating cycle of one year or more, including monetary funds, short-term investments, notes receivable, accounts receivable and inventories. Current liabilities, also known as short-term liabilities, refer to debts that will be repaid within one business cycle of one year or more, including short-term loans, notes payable, accounts payable, advance receipts, dividends payable, taxes payable, and others. Provisional payables, accrued expenses and long-term loans due within one year.

2) Quick ratio

The quick ratio is the ratio of quick assets to current liabilities. It is a measure of the ability of an enterprise's current assets to be immediately realized for repayment of current liabilities. Quick-moving assets, including monetary funds, short-term investments, notes receivable, accounts receivable and other receivables, can be realized in a shorter period of time. Inventories in current assets and non-current assets due within 1 year should not be included.

\subsection{Profitability Indicator}

1) Net profit margin

The net profit margin refers to the relationship between the company's net profit and sales revenue, which is used to measure the ability of the company to obtain sales income in a certain period of time. How much operating profit can be earned by this indicator fee. Also known as the net profit margin of sales, it is the percentage of net profit to sales revenue. This indicator reflects the amount of net profit generated by each dollar of sales revenue, indicating the level of income from sales revenue. 


\section{2) Return on net assets}

Rate of return on net assets, also known as rate of return on equity/net rate of return/rate of return on equity/rate of equity profit margin/rate of net profit margin, is the percentage of net profit to average shareholders' equity, which is the percentage of the company's after-tax profit divided by net assets. It reflects the level of return on shareholders' equity, which is used to measure the efficiency of the company's use of its own capital. The higher the indicator value, the higher the return on investment. This indicator reflects the ability of its own capital to obtain a net return. In general, an increase in liabilities leads to an increase in the return on equity.

3) Total net asset interest rate

The total net asset interest rate is referred to as ROA, which is the ratio of the net profit of the enterprise to the average total assets in a certain period of time. The higher the net profitmargin of the assets, the stronger the profitability of the company's use of all assets; the lower the net profit margin of the assets, the weaker the profitability of the company's use of all assets. The net profit margin of assets is directly proportional to net profit and inversely proportional to the average total assets. The net profit margin of assets is the most important indicator affecting the profit margin of the owner's equity. It has a strong comprehensiveness, and the net profit margin of the assets depends on the sales net profit rate and the asset turnover rate.

\subsection{Operating Capacity Indicator}

1) Property ratio

The equity ratio is the ratio of total liabilities to total owner's equity. It refers to the ratio of the total liabilities to the total equity of the joint-stock enterprise, which is an indicator for assessing the rationality of the capital structure. Generally speaking, the ratio of property rights may reflect whether the equity held by the shareholders is excessive or insufficient, and the other aspect indicates the degree of business borrowing. This ratio is one of the indicators for measuring a company's long-term solvency. It is an important indicator of the soundness of a company's financial structure. This indicator shows the relative relationship between the creditor's and the source of funding provided by the investor, reflecting whether the company's basic financial structure is stable.

2) Total Assets Turnover rate

The total asset turnover rate refers to the ratio of the net business income of an enterprise to the average total assets during a certain period of time. The total asset turnover rate is an important indicator for comprehensively evaluating the operational quality and utilization efficiency of all assets of an enterprise. The higher the turnover rate, the faster the total asset turnover, reflecting the stronger sales ability. Enterprises can accelerate the turnover of assets through the method of small profits but quick turnover, resulting in an increase in the absolute amount of profits. 
3) Current asset turnover

The current assets turnover rate refers to the ratio of the net income of the main business to the average total current assets in a certain period of time. The current asset turnover rate is an important indicator for evaluating the asset utilization rate of enterprises.

The current asset turnover rate reflects the turnover rate of the company's current assets. It analyzes the utilization efficiency of the company's assets from the perspective of the most liquid assets in the company's assets, so as to further reveal the main factors affecting the quality of the company's assets.

\subsection{Growth Ability Index}

1) Main business income growth rate

The main business income growth rate can be used to measure the company's product life cycle and determine the stage in which the company is developing. Generally speaking, if the main business income growth rate exceeds $10 \%$, it indicates that the company's products are in the growth stage, will continue to maintain a good growth momentum, and have not yet faced the risk of product renewal, belonging to growth companies. If the growth rate of the main business income is between $5 \%$ and $10 \%$, it indicates that the company's products have entered a stable period and will soon enter a recession period, and it is necessary to start developing new products. If the ratio is lower than $5 \%$, the company's products have entered a recession period. It has been difficult to maintain market share. The profit of the main business has started to decline. If there are no new products developed, it will decline.

2) Total operating cost growth rate

The total operating cost growth rate is used to measure the company's control over operating costs, reflecting the company's management of the company's cost and the progress of corporate efficiency.

\section{Theoretical Basis and Method}

\subsection{Factor Analysis}

\subsubsection{The Concept of Factor Analysis and the Meaning of Use}

The factor analysis method proposed by Fruchter (1954) is an important analytical method in multivariate statistical analysis. Its basic purpose is to use a few factors to describe the relationship between multiple indicators or factors [6]. By categorizing several variables that are close together in the same class, and classifying each type of variable into a factor, we can reflect most of the information of the original observation data with fewer factors.

\subsubsection{Establishing Model Theory Steps for Factor Analysis}

1) Data processing

First, suppose there are m company companies, and each company has $\mathrm{n}$ company performance evaluation index variables. Based on the differences in the data units queried in this paper, in order to avoid the adverse consequences 
caused by the differences in the scale of observation and its magnitude, it is necessary to standardize the data of the sample observation data, and the sample data matrix after the standardization is:

$$
X=\left[\begin{array}{cccc}
X_{11} & X_{12} & \cdots & X_{1 n} \\
X_{21} & X_{22} & \cdots & X_{2 n} \\
\cdots & \cdots & \cdots & \cdots \\
X_{m 1} & X_{m 2} & \cdots & X_{m n}
\end{array}\right]
$$

Among them, the vector coefficient of $X$ is an observable random variable, and its mean is $E(X)=0$, and the covariance matrix $\operatorname{COV}(X)=1$.

2) KMO and Bartlett spherical test for the feasibility of decision factor analysis

KMO statistic: The correlation between variables is judged by comparing the simple correlation coefficient and the partial correlation coefficient between variables. When the correlation is strong, the partial correlation coefficient is much smaller than the simple correlation coefficient, and the KMO value is close to 1 . In general, $\mathrm{KMO}>0.9$ is very suitable for factor analysis; $0.7<\mathrm{KMO}<0.9$ is suitable; 0.6 or above is acceptable, and 0.5 or less is not suitable for factor analysis.

Bartlett's Ball Test (Bartley Spherical Test): Used to check if the correlation matrix is a unit matrix, that is, whether the variables are independent. It is based on the matrix of correlation coefficients of variables, and the null hypothesis: the matrix of correlation coefficients is a unit matrix. If the statistical value of the Bartley spherical test is large and the corresponding companion probability value is less than the level of significance given by the user, the null hypothesis should be rejected; otherwise, the null hypothesis cannot be rejected, and the correlation coefficient matrix may be a unit matrix. Not suitable for factor analysis. If the hypothesis cannot be denied, it means that these variables may provide some information independently and lack common factors.

3) Calculate the correlation coefficient matrix $R$ as:

$$
\left[\begin{array}{llll}
r_{11} & r_{12} & \cdots & r_{1 n} \\
r_{21} & r_{22} & \cdots & r_{1 n} \\
\cdots & \cdots & \cdots & \cdots \\
r_{m 1} & r_{11} & \cdots & r_{m n}
\end{array}\right]
$$

4) Perform factor analysis and calculate eigenvalues and eigenvectors of the observed data

The simple step is: let $/ R-\lambda I /=0$, find the eigenvalue, the eigenvalue vector.

5) Calculating the factor load matrix $A$ is:

$$
\left[\begin{array}{cccc}
a_{11} & a_{12} & \cdots & a_{1 n} \\
a_{21} & a_{22} & \cdots & a_{1 n} \\
\cdots & \cdots & \cdots & \cdots \\
a_{m 1} & a_{11} & \cdots & a_{m n}
\end{array}\right]
$$

6) Factor extracting principal component

Select $p(p<n)$ principal factors (marked with $F)$ so that the sum of the variance contribution rates of the $p$ principal factors accounts for more than $85 \%$ 
of the total variance contribution rate, or the eigenvalue corresponding to the main factor is greater than 1, then it means that these main factors basically retain the information of the original analysis indicators, and reduce the original $\mathrm{n}$ analysis indicators to $p$ factors, achieving the purpose of simplifying the analysis index optimization model.

7) Establish a factor model of related meaning

$$
\left\{\begin{array}{l}
x_{1}=a_{11} F_{1}+a_{12} F_{2}+\cdots+a_{1 p} F_{p}+\varepsilon_{1} \\
x_{2}=a_{21} F_{1}+a_{22} F_{2}+\cdots+a_{2 p} F_{p}+\varepsilon_{2} \\
\cdots \\
x_{n}=a_{n 1} F_{1}+a_{n 2} F_{2}+\cdots+a_{n p} F_{p}+\varepsilon_{n}
\end{array}\right.
$$

The element $a_{i j}$ in matrix $\mathrm{A}$ is called the factor load, and the absolute value of $a_{i j}$ is less than 1 . If the value of $a_{i j}$ is larger, the closer to 1 , the greater the correlation between $X_{i}$ and $a_{i p}$ that is, the larger the load of the common factor $a_{i j}$ for $X_{i}$. We call the common factor load, or the load of the factor, the matrix A is called the factor load matrix.

8) Variance maximum orthogonal rotation

After the first factor analysis, it is necessary to find out from the factor load table whether each principal factor is related to the relevant information of the original observation data, and to sum up the information it contains to find new ideas, factors in the new sense. Only have an explanatory power on the sample. If the factor load table shows that the factor has little correlation with the original index, that is, the factor load at this time does not satisfy the "simple structural criterion", the typical representative variables of each factor are not very prominent, which makes us unable to make meaning explanation to the factor. To do this, it is necessary to rotate the factor load so that the square of the factor load is transformed from 0 to 1 in order to achieve the purpose of simplifying the structure and clear meaning of the factor interpretation. There are many ways to rotate a factor. Here I use the maximum orthogonal rotation of the variance, which is an orthogonal rotation of the factor load, which allows the rotated factor load matrix to maximize the variance of the squared data while keeping the columns orthogonal to each other.

9) Factor score and sort

The factor score is calculated based on the factor load table. First, the meaning of the factor is expressed according to the information in the factor load table, and then the factor score is calculated by the linear sum of the factor load and the original observation index corresponding to each enterprise. Finally, the variance of the factor is calculated. The contribution rate as a weight weights the three factor scores of each enterprise and the cumulative interpretation variance contribution rate of the three factors can obtain the total factor scores of each enterprise, and then rank.

\subsection{K-Means Clustering Algorithm}

The K-means algorithm is the most commonly used clustering algorithm and is 
proposed by MacQueen J [7]. The main idea is to assign each point to the nearest cluster center in the case of the initial $k$ center point. Then, based on all the points in a cluster, the center point is recalculated by averaging until the change in the center point is small, or the specified number of iterations is reached. Suppose the sample is $X=\left\{X_{1}, X_{2}, \ldots, X_{n}\right\}$ where each object has attributes of $\mathrm{m}$ dimensions. The goal of the $\mathrm{K}$-means algorithm is to aggregate $\mathrm{n}$ objects into the specified $k$ clusters based on the similarity between objects. Each sample belongs only to the cluster with the smallest distance. For K-means, you first need to initialize $k$ cluster centers $\left\{C_{1}, C_{2}, C_{3}, \ldots, C_{k}\right\}$, and then calculate the Euclidean distance from each object to each cluster center, such as

$$
\left\{\operatorname{dis}\left(X_{i}, C_{j}\right)=\sqrt{\sum_{t=1}^{m}\left(X_{i t}-C_{j t}\right)}\right.
$$

where $X_{i}$ represents the $i$-th sample, $C_{j}$ represents the $j$-th cluster center, $\mathrm{X}_{\mathrm{it}}$ represents the $t$-th attribute of the $i$-th sample, and $C_{j t}$ represents the $t$-th attribute of the $j$-th cluster center. The distance from each sample to the center point is compared in turn, and the sample is assigned to the class with the smallest distance.

\section{Empirical Analysis}

The data in this paper are all from the Wind database. In total, the financial data of the 71 mid-year reports of 71 new three-board listed companies in semiconductor and semiconductor production equipment were extracted, and 10 solvency, profitability, operational capability and growth capacity were selected. Specifically, the solvency includes a current ratio and a quick ratio; the profitability includes a sales net profit ratio, an asset return ratio, and a total asset net profit ratio; the operating capacity includes a property ratio, a total asset turnover ratio, and a current asset turnover ratio; and the growth capability includes Main business income growth ratio, total operating cost growth ratio. The financial indicators study the operating performance of the listed companies in the New Third Board.

\subsection{KMO and Bartlett Spherical Test}

$\mathrm{KMO}$ and Bartlett spherical tests are required on the sample data before principal component analysis to determine whether the sample data of each industry is suitable for establishing a factor analysis model. The results of the KMO and Bartlett's spherical test are shown in Table 1 .

The KMO test is used to check the partial correlation between variables, ranging from 0 to 1 . The closer the KMO statistic is to 1 , the stronger the partial correlation between the variables, and the better the effect of factor analysis. In the actual analysis, the KMO statistic is better than 0.7; the KMO statistic is between 0.6 and 0.7. When the KMO statistic is below 0.5 , the factor analysis method is not suitable at this time, and the redesign variable should be considered. Structure or use other statistical analysis methods. The Bartlett spherical test 
Table 1. KMO and Bartlett's test results.

\begin{tabular}{rcc}
\hline KMO test & KMO value & 0.6 \\
\hline & Chi-Squared & 414.8 \\
Bartlett test & $\mathrm{df}$ & 70 \\
& $p$ & 0.0 \\
\hline
\end{tabular}

Note: Raw data comes from the Wind database.

judges that if the correlation matrix is a unit matrix, the independent factor analysis method of each variable is invalid. The results of the $\mathrm{R}$ language test show that the $p$ value is less than 0.05 , indicating that there is correlation between the variables, and the factor analysis is effective. As can be seen from Table 1, the KMO values corresponding to the sample data of the semiconductor and semiconductor manufacturing equipment industry and the energy II industry are 0.6 and 0.62 , respectively, less than 0.7 , indicating that a factor analysis model can be established. The $p$-values determined by Bartlett's spherical test are all close to 0 (less than 0.05 ), indicating that there is correlation between the variables, and the factor analysis is effective. Therefore, we will initially analyze the nature and characteristics of the industry by establishing a factor analysis model for the semiconductor and semiconductor manufacturing equipment industry.

\subsection{Factor Analysis in the Semiconductor Industry}

In this paper, $\mathrm{R}$ statistical software is used to analyze the standardized observation data, and the total variance interpretation Table 2 can be obtained. It can be seen that the first line of the data reflects the information of the main factor 1 that is the variance of Factorl, the characteristic value is 3.533603 , Factorl can explain the total variance of $35.33603 \%$; the second line represents the main Factor 2 that is Factor 2 The information of variance interpretation has a characteristic value of 1.999135 , and the variance interpretation degree Vars. Prop is 19.9913\%; the third line is the related information of the third factor Factor3, and its eigenvalue is 1.566022 , which can explain the total variance of $15.6662 \%$. The four rows are related information of the fourth factor Factor4, and its eigenvalue is 1.083064 , which can explain $10.8306 \%$ of the total variance. The eigenvalues of the three factors are obviously greater than 1 , and their contribution rate of cumulative variance interpretation reaches $81.81,823 \%$. In summary, the cumulative contribution rate of these four factors is about $85 \%$, so it can be considered that these four factors are enough to replace the original observation data indicators to evaluate the performance of high-tech companies. To evaluate the performance of semiconductor and semiconductor manufacturing equipment companies.

It can be seen from Table 3 that the first factor Factor 1 corresponds to the variable return on equity, and the factor load of the total return on assets is relatively large, both exceeding 0.8 , but the factor load values corresponding to other variables do not show significant Small land, such as variable current asset turnover 
Table 2. Semiconductor industry factor variance and its contribution rate.

\begin{tabular}{lccc}
\hline & Vars & Vars.Prop & Vars.Cum \\
\hline Factor 1 & 3.533603 & 0.35336 & 35.33603 \\
Factor2 & 1.999135 & 0.199913 & 55.32738 \\
Factor3 & 1.566022 & 0.156602 & 70.9876 \\
Factor4 & 1.083064 & 0.108306 & 81.81823 \\
\hline
\end{tabular}

Note: Raw data comes from the Wind database.

Table 3. Factor load table before rotation in the semiconductor industry.

\begin{tabular}{ccccc}
\hline Indicator name & Factor 1 & Factor2 & Factor3 & Factor4 \\
Current ratio & -0.15811 & 0.872329 & 0.009974 & -0.03835 \\
Quick ratio & -0.40797 & 0.718121 & 0.052804 & -0.07593 \\
Property ratio & 0.370565 & -0.68025 & -0.00852 & 0.044884 \\
Sales margin & 0.54012 & 0.364093 & -0.19909 & 0.533045 \\
Roe & 0.825497 & 0.046097 & -0.27176 & 0.313222 \\
Total net asset interest rate & 0.800789 & 0.20778 & -0.37664 & 0.174437 \\
Current asset turnover & 0.773575 & 0.041083 & 0.00946 & -0.57867 \\
Total asset turnover & 0.775462 & 0.230163 & -0.07804 & -0.53584 \\
Main business income growth rate & 0.442597 & 0.164941 & 0.794212 & 0.129303 \\
Total operating cost growth rate & 0.441314 & -0.00314 & 0.819002 & 0.149789 \\
\hline
\end{tabular}

Note: Raw data comes from the Wind database.

rate and total asset turnover rate, the corresponding factor load value has reached 0.7 and close to 0.8 , and the load values corresponding to other variables also have a large proportion, so the economic meaning of Factor 1 is not so obvious. The second principal factor Factor2, the absolute value of the factor load value on the variable flow ratio exceeds 0.8 , but the factor load value corresponding to other variables is not significantly smaller, so the economic meaning of Factor 2 is not ideal.

Similarly, Factor 3 and Factor4 have the same problem. For this case, the maximum variance orthogonal rotation method can be considered to rotate the factor load, and Table 4 is obtained by $\mathrm{R}$ language software.

The rotated factor load matrix can be seen from the factor load matrix after the variance maximization rotation. Each factor in the current factor load matrix has a clear interpretation of the original observation factor compared to the initial factor load matrix. According to the correlation, a variable corresponding to the absolute value of the factor load value greater than 0.8 is selected from each of the factors as an explanatory aspect of each factor. That is, the first principal factor, Factorl, selects the net profit margin, the return on net assets, and the net profit margin as the explanatory aspect; the second principal factor, Factor2, selects the current ratio and the quick ratio as an explanatory aspect; the third 
Table 4. Factor load table after rotation.

\begin{tabular}{ccccc}
\hline Indicator name & Factor 1 & Factor 2 & Factor3 & Factor4 \\
\hline Current ratio & 0.11341 & 0.878214 & 0.05283 & 0.02481 \\
Quick ratio & -0.12933 & 0.814301 & -0.09626 & -0.0401 \\
Property ratio & 0.080058 & -0.76262 & 0.09916 & 0.06561 \\
Sales margin & 0.845254 & 0.126875 & -0.01457 & 0.13154 \\
Roe & 0.837015 & -0.24782 & 0.29206 & 0.09065 \\
Total net asset interest rate & 0.82322 & -0.08019 & 0.41460 & -0.0264 \\
Current asset turnover & 0.158946 & -0.15396 & 0.92750 & 0.16070 \\
Total asset turnover & 0.27207 & 0.017543 & 0.92846 & 0.10559 \\
Main business income growth rate & 0.101923 & 0.040374 & 0.13426 & 0.91681 \\
Total operating cost growth rate & 0.057173 & -0.119 & 0.09242 & 0.92843
\end{tabular}

Note: Raw data comes from the Wind database.

principal factor, Factor3, selects the current asset. The turnover rate and total asset turnover rate are used as explanations; the fourth main factor, Factor4, selects the main business income growth rate and the total operating cost growth rate as an explanation, and is obtained in Table 5.

As can be seen from the above factor explanation Table 5, the first principal factor Factor1 mainly explains the three indicators of sales net interest rate, return on net assets, and net profit margin of total assets, which represent the profitability of the enterprise, so it can be called Profit1. The ability factor; the second principal component Factor2 mainly explains the current ratio and the quick ratio, which represents the solvency of the enterprise, so Factor2 can be called the solvency factor; the third principal factor Factor3 mainly explains the turnover rate of the current assets, Total asset turnover rate, these two indicators are important indicators for evaluating the operational capabilities of semiconductor and semiconductor manufacturing equipment companies, so Factor3 can be called operational capacity factor, while Factor4 mainly explains operating income growth rate and total operating cost growth rate (Taking the opposite, it evaluates the growth ability of semiconductor manufacturing equipment companies, so Factor4 can be called the growth ability factor. Moreover, according to the variance contribution Table 6 after rotation, we can know that the variance contribution of the four principal factors is almost equal, which indicates that these four principal factors have a considerable influence in evaluating the performance evaluation of semiconductor and semiconductor equipment manufacturers.

\subsection{Comprehensive Score and Ranking Analysis}

After extracting the main factors, we can use factor scores and comprehensive scores to initially compare the goodness of semiconductor and semiconductor equipment manufacturers, and provide some reference for investors. According 
Table 5. Factor explanation table.

\begin{tabular}{lc}
\hline Factor & Variable \\
\hline Factor 1 & Net profit margin; Return on net assets; Net profit margin \\
Factor 2 & Current ratio; Quick ratio \\
Factor 3 & Current assets turnover rate; Total asset turnover rate \\
Factor 4 & Operating income growth rate; Total operating cost growth rate \\
\hline
\end{tabular}

Table 6. Variance contribution table after rotation.

\begin{tabular}{lccc}
\hline & Vars & Vars.Prop & Vars.Cum \\
\hline Factor1 & 2.24168 & 22.4168 & 22.4168 \\
Factor2 & 2.139687 & 21.39687 & 43.81366 \\
Factor3 & 2.028189 & 20.28189 & 64.09555 \\
Factor4 & 1.772268 & 17.72268 & 81.81823 \\
\hline
\end{tabular}

Note: Raw data comes from the Wind database.

to the extraction of the main factor, the comprehensive score evaluation model that can be constructed is:

$$
\begin{aligned}
F= & (22.4168 \times \text { Factors } 1+21.39687 \times \text { Factors } \\
& +20.28189 \times \text { Factors } 3+17.72268 \times \text { Factors } 4) / 0.8181823
\end{aligned}
$$

According to this scoring model, a factor comprehensive score table of 71 samples can be obtained (Table 7).

In the factor scores in Table 7, since the selected indicators are all positive indicators, and the selected principal factors correspond to the factor load values of the respective explanatory variables are positive numbers, the value greater than zero indicates the ability of the enterprise to correspond (for example Factor 1 represents a company's profitability.) If the value is negative, it means that the company's corresponding ability is poor. Investors can cautiously enter the market according to the results of the analysis.

\subsection{Cluster Analysis}

Using the K-means fast clustering method, we first find out that the center number $\mathrm{k}$ is 4 by system clustering. Furthermore, the $\mathrm{K}$-means clustering center is set to 4 , and the calculation of the $\mathrm{R}$ language can be used to obtain Table 8.

From K-means clustering results Table 8, we can know that there are a total of 20 companies classified as the first category, namely, Dinghui Technology Runda Photovoltaic, Core Energy Technology, Ningyu Technology, Zhanxinwei, Jiasheng Optoelectronics, Europe Nair, Fuyouchang, Juyuanwei, Ai Nengju, Jiake Energy and other companies; there are also 20 companies in the second category, namely Aubek, Quanhua Optoelectronics, Jiuzhou Optoelectronics, Sco Electrical, Zhonghao Optoelectronics, Bitley, Guanyu Technology, Qirui Shares, Deep Love, Jinshang Xinneng, Boyuan Hi-Tech and other companies; 15 companies classified as the third category, namely Zhonghaiyang, Poly Lighting, 
Table 7. Comprehensive scores of some enterprise factors in the semiconductor industry.

\begin{tabular}{ccccccc}
\hline Company Name & Factor 1 & Factor2 & Factor3 & Factor4 & Synthesis score & Rankings \\
\hline O’Neill & 0.51 & 1.14 & 4.59 & -1.08 & 1.34 & 1 \\
Yinggu shares & -0.24 & 1.35 & 2.67 & 1.67 & 1.31 & 2 \\
Nanochip & 1.84 & 1.31 & 0.08 & -0.20 & 0.82 & 3 \\
Jiasheng Photoelectric & 0.28 & 1.15 & 2.13 & -0.50 & 0.79 & 4 \\
Lishengmei & 0.77 & 1.37 & 0.34 & 0.53 & 0.77 & 5 \\
Sco Electric & -1.69 & 0.53 & -1.07 & -0.45 & -0.69 & 67 \\
Vestek & -1.49 & 0.03 & -0.98 & -0.68 & -0.79 & 68 \\
Aubek & -0.87 & -0.71 & -0.86 & -0.75 & -0.80 & 69 \\
Jiuzhou Optoelectronics & -1.19 & -1.19 & -0.66 & -0.64 & -0.94 & 70 \\
Yourun Electronics & -1.59 & -2.87 & 0.77 & -0.64 & -1.13 & 71 \\
\hline
\end{tabular}

Note: Raw data comes from the Wind database.

Table 8. Partial K-means clustering results.

\begin{tabular}{|c|c|c|c|c|c|}
\hline Company Name & Factor 1 & Factor 2 & Factor3 & Factor4 & Category \\
\hline Dinghui Technology & 0.32 & -0.74 & -0.5 & -0.9 & 1 \\
\hline Runda Photovoltaic & 0.43 & -0.38 & 1.16 & -0.08 & 1 \\
\hline Core Energy Technology & 0.53 & -0.41 & -0.06 & -1.82 & 1 \\
\hline Ning Yu Technology & 0.77 & 1.28 & -0.68 & -1.23 & 1 \\
\hline Exhibition core micro & -0.38 & -0.81 & 0.2 & -0.95 & 1 \\
\hline Jiasheng Photoelectric & 0.28 & 1.15 & 2.13 & -0.5 & 1 \\
\hline O’Neill & 0.51 & 1.14 & 4.59 & -1.08 & 1 \\
\hline Fu Youchang & -0.58 & 1.43 & 0.53 & -1.04 & 1 \\
\hline Aubek & -0.87 & -0.71 & -0.86 & -0.75 & 2 \\
\hline Quanhua Optoelectronics & -0.33 & 0.59 & -0.8 & -0.81 & 2 \\
\hline Jiuzhou Optoelectronics & -1.19 & -1.19 & -0.66 & -0.64 & 2 \\
\hline Sco Electric & -1.69 & 0.53 & -1.07 & -0.45 & 2 \\
\hline Kyushu Fangyuan & 2.55 & -1.07 & -2.11 & 0.3 & 3 \\
\hline Jiejia Weichuang & 0.08 & -0.9 & -0.55 & 0.07 & 3 \\
\hline Hang Seng Technology & -0.03 & -0.83 & -0.25 & 1.06 & 3 \\
\hline Lishengmei & 0.77 & 1.37 & 0.34 & 0.53 & 4 \\
\hline Mega Technology & -0.64 & 1.94 & -0.37 & 1.24 & 4 \\
\hline Core electronic & 0.7 & 0.22 & 0.89 & 0.55 & 4 \\
\hline Nanochip & 1.84 & 1.31 & 0.08 & -0.2 & 4 \\
\hline Core integration & 0.75 & 0.14 & -0.03 & 0.44 & 4 \\
\hline
\end{tabular}

Note: Raw data comes from the Wind database.

Shanghui Energy, Liyang Chip, Kyushu Fangyuan and other companies; there are 16 companies classified as the fourth category, namely Xinsong Jiahe, Tong- 
hui Information, Yanwei Power, Yinggu Shares, Boshuo Photoelectric And other companies.

After determining the initial classification of the company, we can further analyze the same nature of the companies in the same category, so that when establishing the discriminant analysis model, we can clarify the actual meaning of each category and provide investors with decision-making reference.

According to Figure 1 and Figure 2 of the K-means Cluster Center, we can determine the relative position of each category corresponding to different capabilities, because the cluster data we use is the factor score, and the indicators used in the original data are evaluation semiconductors. And the positive indicators of the performance of semiconductor equipment manufacturers, the higher the factor score of the corresponding company, the better the company's ability to respond to this factor, and vice versa. We can roughly think that the factor score is less than zero, the factor score is near zero, and the factor score is significantly better than zero. Therefore, from the above two cluster center maps, we can conclude that the nature of different types of enterprises, see Table 9.

\section{Conclusions}

We have evaluated and analyzed the solvency, profitability, operational capabilities and growth capabilities of the semiconductor and semiconductor equipment manufacturing industries by establishing appropriate models.

Table 9. Nature of different types of companies in the semiconductor industry.

\begin{tabular}{ccccc}
\hline Category & Profitability & Solvency & Operating capacity & Growth ability \\
\hline 1 & good & good & excellent & poor \\
2 & poor & poor & poor & good \\
3 & excellent & poor & poor & excellent \\
4 & good & excellent & good & excellent \\
\hline
\end{tabular}

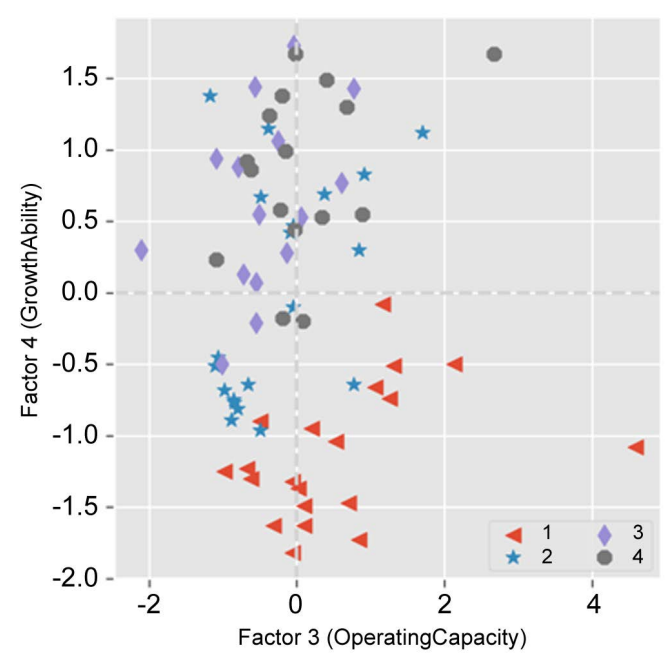

Figure 1. K-means cluster center. 


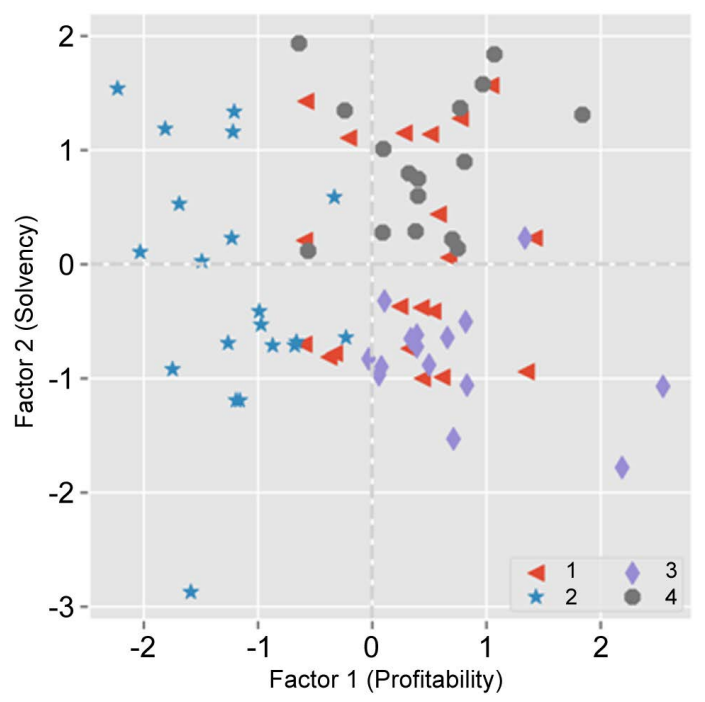

Figure 2. K-means cluster center.

For the semiconductor and semiconductor manufacturing equipment industry, through factor analysis, we found that four representative principal factors can be extracted from many original indicators. The cumulative contribution rate of the four principal factors to the data interpretation exceeds $80 \%$, and the eigenvalue corresponding to each principal factor is greater than 1 . This shows that the extracted four common factors have good interpretation ability for the sample data. Therefore, after calculating the main factor score and the comprehensive score, investors can use the information provided by the four main factors to make a pre-decision reference. Furthermore, after the maximum variance orthogonal rotation, the economic interpretation of each principal factor is more clear. In the semiconductor and semiconductor manufacturing equipment industry, the first main factor Factorl represents profitability, the second main factor Factor2 represents solvency, the third main factor Factor3 represents operational capability, and the fourth main factor Factor4 represents growth capability. Among them, the profitability factor accounts for the largest share of variance contribution. This shows that when evaluating the performance of semiconductor and semiconductor manufacturing equipment companies, investors should pay special attention to the profitability of enterprises, but also pay attention to the performance of other capacity indicators to minimize the risk of investment. After factor analysis to obtain a reasonable main factor score, we used the data of the main factor score for cluster analysis. First, we performed multiple systematic clustering by random sampling to determine the reasonable number of classification categories. Then, the original sample is initially classified by K-means clustering method. Finally, it summarizes the nature of the enterprise and provides a statistical reference for investment decisions.

\section{Conflicts of Interest}

The author declares no conflicts of interest regarding the publication of this paper. 


\section{References}

[1] Zhou, M.Q. and Yin, Z.L. (2011) The Formation, Function and Development Trend of the "New Third Board". Contemporary Economy \& Management, 2.

[2] Pan, Y.J. (2011) China's New Third Board Transfer Mechanism and Its Reference to International Experiences. Commodity \& Quality, S7, 106-107.

[3] Wei, S.J. (2013) Research on the Promotion of Corporate Finance and Venture Capital Withdrawal by the New Third Board. China Science and Technology Forum, 5, 137-142.

[4] Wu, X.Z. (2011) Financial Crisis Early Warning Research: Existing Problems and Framework Reconstruction. Accounting Research, 2, 59-65, 97.

[5] Ye, H.Z., Yang, Q. and Wang, Y.H. (2013) Study on Intelligent Financial Crisis Early Warning and Cause Diagnosis Method-Based on Adaptive Bayesian Network Model SABNM. Audit and Economic Research, 3, 74-82.

[6] Fruchter, B. (1954) Introduction to Factor Analysis.

[7] Macqueen, J. (1965) Some Methods for Classification and Analysis of MultiVariate Observations. Proceedings of Berkeley Symposium on Mathematical Statistics \& Probability, 14, 281-297. 